\title{
Utility of C-Reactive Protein and Procalcitonin for Detecting Bloodstream Infection in Patients with HIV/AIDS
}

\author{
Arianna Castillo Marshall', Tersilia García Castellanos², Isabel Martínez Motas³, \\ Daniel Salazar Rodriguez ${ }^{1}$, María Eugenia Toledo Romaní ${ }^{\text {, J Jorge Pérez Ávila }}{ }^{5}$ \\ ${ }^{1}$ Department of Clinical Microbiology, Institute of Tropical Medicine "Pedro Kourí", La Havana, Cuba \\ ${ }^{2}$ Clinical Laboratory, International Health Center La Pradera, La Havana, Cuba \\ ${ }^{3}$ Medicine Faculty, Latin-American's School, La Havana, Cuba \\ "Epidemiology Research Department, Institute of Tropical Medicine "Pedro Kouri", La Havana, Cuba \\ ${ }^{5}$ Institute of Tropical Medicine "Pedro Kouri", La Havana, Cuba \\ Email: gustavorpnegromonte@gmail.com
}

Received 15 June 2014; revised 10 July 2014; accepted 3 August 2014

Copyright (C) 2014 by authors and Scientific Research Publishing Inc.

This work is licensed under the Creative Commons Attribution International License (CC BY).

http://creativecommons.org/licenses/by/4.0/

(c) () Open Access

\begin{abstract}
Human immunodeficiency virus (HIV) infected persons, are at high risk for developing a bloodstream infection. In order to evaluate the usefulness of C-reactive protein (CRP) and procalcitonin (PTC) in the detection of bloodstream infection in HIV, a case-control study was conducted from February to December 2012. PCT and CPR levels were measured in 2 groups. PCT concentrations were measured by the VIDAS ${ }^{\circledR}$ Brahms PCT assay, and CRP concentrations were determined by CRP latex. Values were calculated for both biomarkers and discriminative ability of PCT and CRP was analyzed using ROC curves. There were no significant differences between the study group and the control groups with respect to CRP levels. However, they were much higher PCT levels in patients with bacteremia. PCT showed greater discriminating ability compared to CRP, and proved to be a valuable tool for the detection of systemic bacterial infections in HIV infected patients.
\end{abstract}

\section{Keywords}

Acute Renal Injury, Surgical Hemostasis, Absorbable Implants, Inflammation, Biocompatible

\section{Introduction}

Human immunodeficiency virus (HIV) infected persons, compared with HIV-negative people have a higher risk 
of developing a bloodstream infection and previous data indicate a high morbidity and mortality, associated with this entity. In most cases the diagnosis depends on obtaining a blood culture at the right time under the right conditions [1].

Blood culture (BC) is still the gold standard of microbiological diagnosis, allowing the identification of the etiologic agent and the study of antimicrobial susceptibility [2]. However, the response time of microbiological studies limits the possibility of an early etiologic diagnosis, for this reason it is useful to have sensitive and specific indicators, whose determination are rapid and correlates with the severity and prognosis of the infection, to differentiate between patients with and without systemic infection. Several blood markers are used for prediction of bacteremia, these include C-reactive protein (CRP) and procalcitonin (PCT) [3] [4].

The CRP is an acute phase reactant, known to respond sensitively to most forms of inflammation infection, and tissue damage. The classical and most widespread use thereof is its application as a marker of bacterial infection and sepsis, which allows knowing the onset of infection, as well as the suitability of treatment [5].

The PCT is a propeptide of the hormone calcitonin (CT), which is normally synthesized by thyroid C cells [6]-[8]. In healthy subjects serum PCT concentration is undetectable, but rises markedly under different situations [9]. Following an infectious stimulus it is detected in serum after 2 - 3 hours, but the maximum peak occurs within 6 - 12 hours and maintained plateau after 24 hours, so it is useful in the treatment and monitoring of critically ill patients [10].

This is the first study which evaluates the usefulness of PCT and CRP as early markers of bloodstream infection of Cubans HIV/AIDS patients.

\section{Materials and Methods}

Study Design: A case-control study in HIV/AIDS patients with a clinical suspicion of bloodstream infection admitted to the Institute of Tropical Medicine Pedro Kourí, was conducted, in the period from February to December 2012.

Universe: 60 patients were selected separated in two groups, 30 cases and 30 controls for a 1:1 ratio.

Cases: Patients who developed a true bacteremia. It was interpreted as the recovery of any significant, pathogenic bacterial species in 1 or 2 sets of blood culture. Organisms commonly considered as BC contaminants (eg, coagulase-negative staphylococci, aerobic and anaerobic diphtheroids, Micrococcus spp, Bacillus spp) were excluded from this definition.

Controls: Patients who do not have developed a true bacteremia. It was defined as negative BC or when contaminating microorganisms were isolate in one $\mathrm{BC}$ set.

Blood culture methods: BC were performed in more than one pair of bottles for aerobic cultures and incubated in the BacT/Alert 3D Blood Culture System (bioMérieux, Durham, NC), which detects the growth of any organism. A small volume of cultured sample was inoculated onto both blood and MacConkey agar plates that were cultured overnight at $35^{\circ} \mathrm{C}$ in incubators. Species identification was achieved by verifying colony morphologies and Gram stain results and by biochemical tests with the Vitek Identification System (bioMérieux, Marcy l'Etoile, France). When no bacteria growth was detected by the BacT/Alert system until five days after primary inoculation of the blood sample the result of the $\mathrm{BC}$ was considered negative.

PCT and CRP assays: To determine the levels of biomarkers, sample taken at the same time as the first blood culture were used. Blood samples from patients were centrifuged, and a portion of the serum was collected. PCT concentrations were measured by the VIDAS ${ }^{\circledR}$ Brahms PCT assay, and CRP concentrations were determined by CRP latex.

Processing and statistical analysis: Student's t was used to compare the mean concentration of markers, expressed with a significance level of 95\%. Receiver operating characteristic (ROC) curves were plotted for PCT and CRP to assess their diagnostic performance for discriminating bacteremia from non-bacteremia and areas under the ROC curves (AUCs) of PCT and CRP were compared. Several performance indicators of procalcitonin for various PCT cutoffs values were also analyzed, using the blood culture as reference. The gold standard was defined as a BC result positive for a pathogen, excluding organisms commonly considered BC contaminants.

\section{Results}

The distributions of CRP concentrations are presented in Figure 1. The mean serum CRP concentrations in the case group were $25.9 \mathrm{mg} / \mathrm{L}$ and $24.3 \mathrm{mg} / \mathrm{L}$ for the control group. There were no significant differences between 
the cases and the controls groups with respect to CRP levels $(p=0.79$ ). The mean serum PCT level was 13.9 $\mathrm{ng} / \mathrm{mL}$ in the case group, which was significantly higher, than in the control groups, which was $0.5 \mathrm{ng} / \mathrm{mL}$ ( $p<$ 0.00) (Figure 2).

The determination of the discriminative ability of CRP and PCT to predict the development of a bloodstream infection was performed using ROC curves. The AUCs of the serum concentration of CRP was 0.47 (95\% CI = 0.32 to 0.62 ), which is below the reference diagonal line (or line of non-discrimination), and its confidence interval included the value of 0.50 (considered the point of no discrimination). PCT AUCs was 0.80 (95\% CI = 0.68 to 0.92 ) which is close to the value 1 (considered perfect discrimination point) (Figure 3). These results suggests that the PCT shows a higher discriminative ability to determine the occurrence of bacteremia, both AUC were statistically compared (Figure 3). There were significant differences between the AUC values of PCT and those of CRP $(p=0.00)$.

In general, the PCT concentrations below $0.5 \mathrm{ng} / \mathrm{mL}$ indicate that bloodstream infection is unlikely. When analyzing the results obtained with different cutoffs, it was observed that $2.32 \mathrm{ng} / \mathrm{mL}$, is the best cutoff point to distinguish HIV patients with and without systemic bacterial infection (Table 1).

\section{Discussion}

To establish an early and accurate diagnosis of an invasive infection is a challenge, since the strategy of its eradication, will be the cornerstone for management. This requires using sensitive and specific indicators of disease

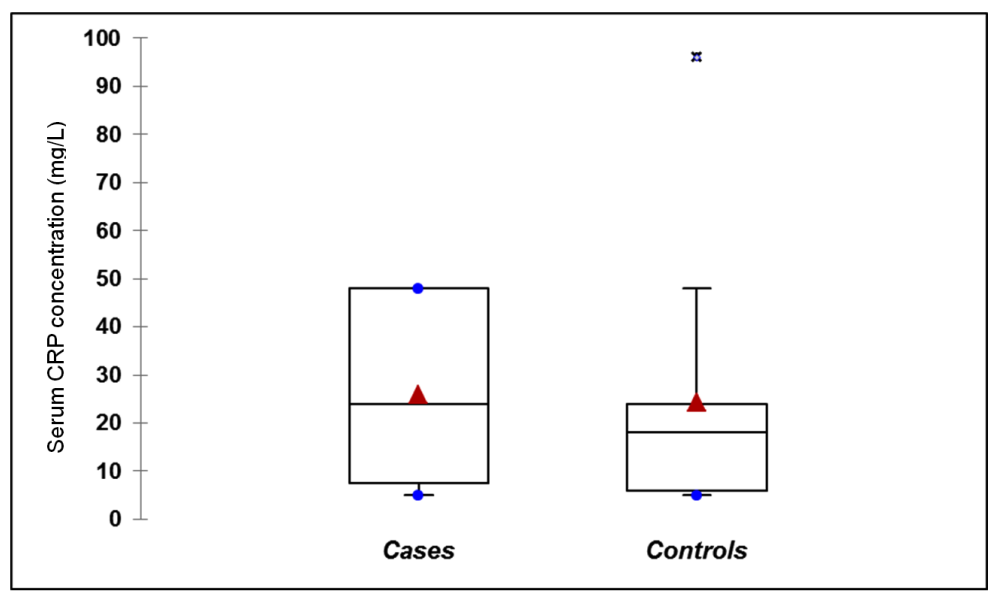

Figure 1. C-reactive protein concentration in cases and control groups. Triangles represent the mean values. Asterisks are outliers $p=0.79$.

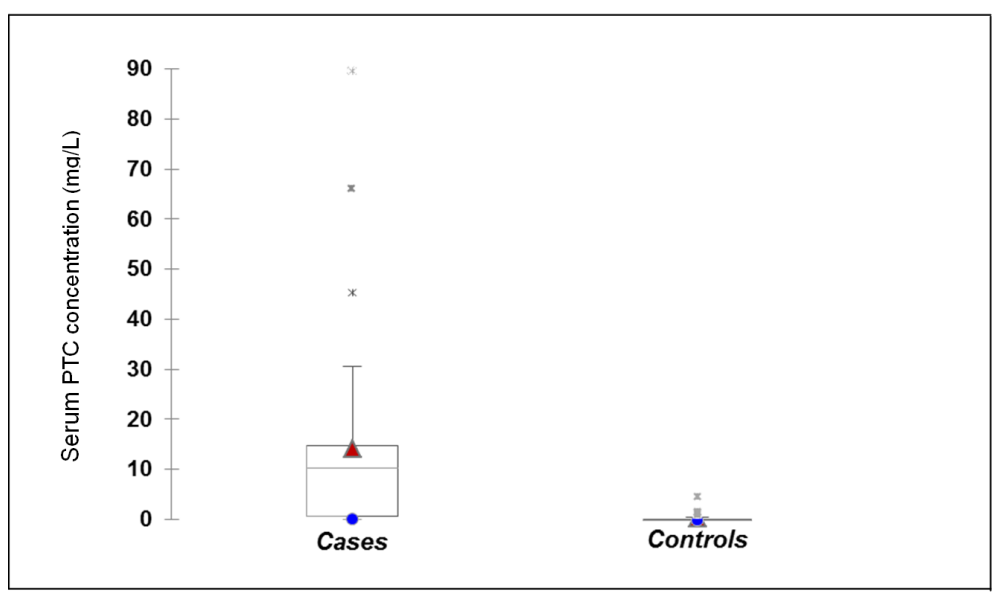

Figure 2. Serum procalcitonin in cases and control groups. Triangles represent the mean values. Asterisks are outliers $p=0.00$. 


\section{ROC curve}

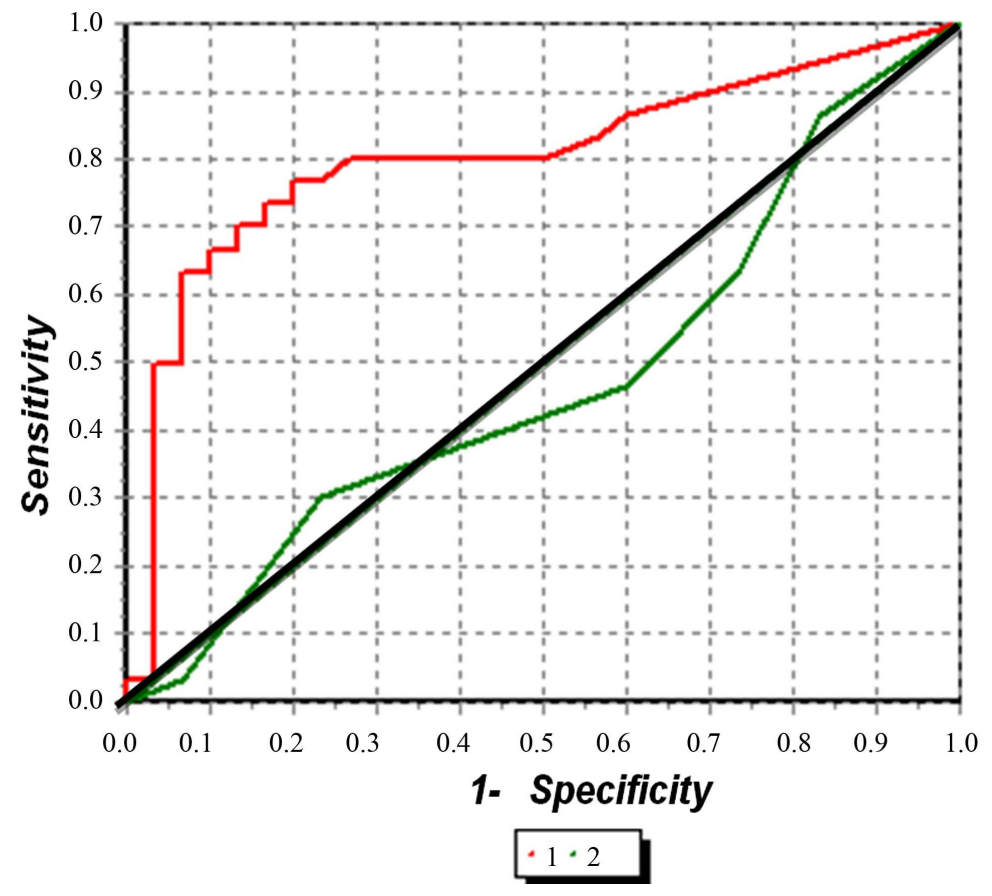

Figure 3. Diagnostic performances of procalcitonin and C-reactive protein for predicting bloodstream infection in HIV. Legend: Curve 1 (PTC: AUCs was $0.80,95 \% \mathrm{CI}=0.68$ to 0.92 ); Curve 2 (PCR: AUCs was $0.47,95 \% \mathrm{CI}=0.32$ to 0.62$), p=0.00$.

Table 1. Performance indicators of procalcitonin with different cutoffs.

\begin{tabular}{ccccccccc}
\hline Breakpoints & Sensitivity & Specificity & PPV & NPV & LR+ & LR- & Youden Index \\
\hline $1.04 \mathrm{ng} / \mathrm{mL}$ & 0.73 & 0.83 & 0.81 & 0.75 & 4.4 & 0.32 & 0.56 \\
$1.25 \mathrm{ng} / \mathrm{mL}$ & 0.7 & 0.86 & 0.84 & 0.74 & 5.25 & 0.34 & 0.56 \\
$1.54 \mathrm{ng} / \mathrm{mL}$ & 0.66 & 0.9 & 0.86 & 0.72 & 6.66 & 0.37 & 0.56 \\
$2.32 \mathrm{ng} / \mathrm{mL}$ & 0.63 & 0.93 & 0.90 & 0.71 & 9.5 & 0.39 & 0.56
\end{tabular}

Legend: positive predictive value (PPV), negative predictive value (NPV), likelihood ratio for a positive result (LR+), likelihood ratio for negative results (RV-).

progression. These should be quickly modified early in the process and respond in the same way with the success of the therapy instituted [11]. CRP is an acute phase reactant which may increase in minor infections therefore it may not adequately reflect the severity of the infection and lacks specificity in differentiating the etiology there of 0.13 Some studies have reported similar results of this investigation [12]. However, Tromp et al. found that these biomarker concentrations are higher in the group of patients with positive blood culture [13].

PCT has become a possible marker of the systemic inflammatory response to infection. Origins of inflammatory PCT are controversial since the production of PCT in the infection phase is not related by thyroid tissues. The exact site of production during sepsis has not been identified, but it has been demonstrated that immunoreactive cells including neutrophils were possible sources of PCT production [14].

Although many studies have established that PCT level can be used to identify bacterial infections in patients with sepsis [15] [16] and the results allowed to state that the PCT, is a good marker to differentiate patients with bacteremia from those who had [17] [18] not only a few studies have evaluated the capacity of PCT findings to rule out bacteremia in HIV patients.

Despite the absence of an AUCs value, from which it appears that a diagnostic method is able to discriminate 
between healthy versus ill patients, when comparing the results, we did not find other studies where the AUCs of CRP, were as low as in this study. Kim et al. [19] describe a AUCs of 0.65, Jeong et al. [10] 0.64 and Tsangaris et al., [20] 0.65. The characteristics of CRP, such as its insufficient specificity, later onset of increase, and vulnerability to immunosuppressant, are probably reflected by these results. Discrepancies found for this parameter may be related to the fact that the techniques used to determine the serum concentration of CRP were different.

With respect to the PTC, AUCs levels, several studies indicate similar results to those in this investigation [21] [22]. By comparing the AUCs values for each marker PCT demonstrate better ability than CRP to differentiate real bloodstream infections. Most of the studies reviewed coincide with this statement [19] [23], but based on the AUCs of PCT, is numerically greater than the PCR. Numerical comparison only suggests which diagnostic test has more power than another [24].

Previous studies have reported the diagnostic accuracy of serum PCT for bacterial infections, but its sensitivity and specificity were variable [25] [26]. These and other publications indicate that the cutoff points are not well defined, which should take into account the following factors: the clinical setting, the location, extent and etiology of the infection, the presence of comorbidity and, in particular, the sensitivity of the assay used and the positive and negative predictive value most be considered. It needs to set specific breakpoints adapted to specific contexts or groups of patients.

\section{Conclusion}

PCT is a more reliable marker for distinguishing bacteremia from non-bacteremic conditions. In the present investigation, the PCT provides valuable information for the diagnosis of systemic infections in HIV/AIDS. However, it is suggested that serial measurements should be made performed to better understand their diagnostic capacity.

\section{References}

[1] Yehia, B., Fleishman, J., Wilson, L., Hicks, P., Gborkorquellie, T. and Gebo, K. (2011) Incidence of and Risk Factors for Bacteraemia in HIV-Infected Adults in the Era of Highly Active Antiretroviral Therapy. HIV Medicine, 12, 535-543.

[2] Loza, E., Planes, A. and Rodriguez, M. (2003) 3a. Hemocultivos 2003. In: Cercenado, E. and Canton, R., Eds., Clinical Microbiology Procedures, Recommendations of the Spanish Society of Clinical Microbiology and Infectious Diseases. http://www.seimc.org/contenidos/documentoscientificos/procedimientosmicrobiologia/seimc-procedimientomicrobiolo gia3a.pdf

[3] Simon, L., Gauvin, F., Amre, D., Saint-Louis, P. and Lacroix, J. (2004) Serum Procalcitonin and C-Reactive Protein Levels as Markers of Bacterial Infection: A Systematic Review and Meta-Analysis. Clinical Infectious Diseases, 39, 206-217. http://dx.doi.org/10.1086/421997

[4] Joo, K., Park, W., Lim, M.-J., Kwon, S.-R. and Yoon, J. (2011) Serum Procalcitonin for Differentiating Bacterial Infection from Disease Flares in Patients with Autoimmune Diseases. Journal of Korean Medical Science, 26, 1147-1151. http://dx.doi.org/10.3346/jkms.2011.26.9.1147

[5] Póvoa, P., Coelho, L., Almeida, E., Fernández, A., Mealha, R., Moreira, P., et al. (2006) Early Identification of Intensive Care Unit-Acquired Infections with Daily Monitoring of C-Reactive Protein: A Prospective Observational Study. Critical Care, 10, R63. http://dx.doi.org/10.1186/cc4892

[6] Gilbert, D. (2010) Use of Plasma Procalcitonin Levels as an Adjunct to Clinical Microbiology. Journal of Clinical Microbiology, 48, 2325-2329. http://dx.doi.org/10.1128/JCM.00655-10

[7] Diaz, R., Oujo, E., Guevara, P., Guillen Campuzano, E., Soria Marin, J.L., Muñoz Pérez, M., et al. (2011) Procalcitonin: Utility and Recommendations for Laboratory Measurement. SEQC Documents. http://www.seqc.es

[8] Limper, M., de Kruif, M., Ajubi, N., van Zanten, A., Brandjes, D., et al. (2011) Procalcitonin as a Potent Marker of Bacterial Infection in Afro-Caribbean Febrile Patients at the Emergency Department. European Journal of Clinical Microbiology \& Infectious Diseases, 30, 831-836. http://dx.doi.org/10.1007/s10096-010-1150-5

[9] Whicher, J., Bienvenu, J. and Monneret, G. (2001) Procalcitonin as an Acute Phase Marker. Annals of Clinical Biochemistry, 38, 483-493. http://dx.doi.org/10.1177/000456320103800505

[10] Jeong, S., Park, Y., Cho, Y. and Kim, H.S. (2012) Diagnostic Utility of Procalcitonin and C-Reactive Protein for the Prediction of Bacteremia Determined to by Blood Culture. Clinica Chimica Acta, 413, 1731-1736. http://dx.doi.org/10.1016/j.cca.2012.06.030 
[11] Prat, C. and Dominguez, J. (2004) Procalcitonin and Markers of Infection. Educación continuada en el laboratorio clínico, 7, 38-43.

[12] Aznar-Oroval, E., Sánchez-Yepes, M., Lorente-Alegre, P., San Juan-Gadea, M.C., Ortiz-Muñoz, B., Pérez-Ballestero, P., Picón-Roig, I. and Maíquez-Richart, J. (2010) Diagnostic Value of Procalcitonin, Interleukin 8, Interleukin 6, and C-Reactive Protein for Detecting Bacteremia and Fungemia in Cancer Patients. Enfermedades Infecciosas Y Microbiologia Clinica, 28, 273-277.

[13] Tromp, M., Lansdorp, B., Bleeker, C., Klein, J., Kullberg, B. and Pickkers, P. (2012) Serial and Panel Analyzes of Biomarkers Do Not Improve the Prediction of Bacteremia Compared to One Procalcitonin Measurement. Journal of Infection, 65, 292-301. http://dx.doi.org/10.1016/j.jinf.2012.06.004

[14] Kim, M.H., Lim, G., Kang, S.Y., Lee, W.I., Suh, J.T. and Lee, H.J. (2011) Utility of Procalcitonin as an Early Diagnostic Marker of Bacteremia in Patients with Acute Fever. Yonsei Medical Journal, 52, 276-281. http://dx.doi.org/10.3349/ymj.2011.52.2.276

[15] Harbarth, S., Holeckova, K., Froidevaux, C., Pittet, D., Ricou, B., Grau, G., et al. (2001) Geneva Sepsis Network Diagnostic Value of Procalcitonin, Interleukin-6, and Interleukin-8 in Critically Ill Patients with Suspected Sepsis Admitted. American Journal of Respiratory and Critical Care Medicine, 164, 396-402. http://dx.doi.org/10.1164/ajrccm.164.3.2009052

[16] Christ-Crain, M., Jaccard-Stolz, D., Bingisser, R., Gencay, M.H., Huber, P.R., Tamm, M., et al. (2004) Effect of Procalcitonin-Guided Treatment on Antibiotic Use and Outcome in Lower Respiratory Tract Infections: Cluster Randomized, Single-Blinded Intervention Trial. The Lancet, 363, 600-607. http://dx.doi.org/10.1016/S0140-6736(04)15591-8

[17] Mauro, M., Cavalcantia, P., Peruginia, D., Notob, A., Sperlìc, D. and Giraldia, C. (2012) Diagnostic Utility of LightCycler Assays SeptiFast and Procalcitonin in the Diagnosis of Bloodstream Infection in Immunocompromised Patients. Diagnostic Microbiology and Infectious Disease, 73, 308-311. http://dx.doi.org/10.1016/j.diagmicrobio.2012.04.006

[18] Koivula, I., Hämäläinen, S., Jantunen, E., Pulkki, K., Kuittinen, T., Nousiainen, T., et al. (2011) Elevated Procalcitonin Predicts Gram-Negative Sepsis in Haematological Patients with Febrile Neutropenia. Scandinavian Journal of Infectious Diseases, 43, 471-478. http://dx.doi.org/10.3109/00365548.2011.554855

[19] Kim, D.Y., Lee, Y.S., Ahn, S., Chun, Y.H. and Lim, K.S. (2011) The Usefulness of Procalcitonin and C-Reactive Protein as Early Diagnostic Markers of Bacteremia in Cancer Patients with Febrile Neutropenia. Cancer Research and Treatment, 43, 176-180. http://dx.doi.org/10.4143/crt.2011.43.3.176

[20] Tsangaris, I., Plachouras, D., Kavatha, D., Gourgoulis, G.M., Tsantes, A., Kopterides, P., et al. (2009) Diagnostic and Prognostic Value of Procalcitonin among Febrile Critically Ill Patients with Prolonged ICU Stay. BMC Infectious Diseases, 9, 213-222. http://dx.doi.org/10.1186/1471-2334-9-213

[21] Riedel, S., Bourbeau, P., Swartz, B., Brecher, S., Carroll, K.C., Stamper, P.D., et al. (2008) Timing of Specimen Collection for Blood Cultures from Febrile Patients with Bacteremia. Journal of Clinical Microbiology, 46, 1381-1385. http://dx.doi.org/10.1128/JCM.02033-07

[22] Charles, P., Ladoire, S., Snauwaert, A., Prin, S., Aho, S., Pechinot, A., et al. (2008) Impact of Previous Sepsis on the Accuracy of Procalcitonin for the Early Diagnosis of Blood Stream Infection in Critically Ill Patients. BMC Infectious Diseases, 8, 163. http://dx.doi.org/10.1186/1471-2334-8-163

[23] Suberviola, B., Castellanos Ortega, A., González Castro, A., Garcia Astudillo, L.A. and Fernández Miret, B. (2011) Prognostic Value of Procalcitonin Clearance, C-Reactive Protein and Leukocytes in Septic Shock. Medicina Intensiva, 36, 177-184. http://dx.doi.org/10.1016/j.medin.2011.09.008 http://dx.doi.org/10.1186/1471-2334-11-224

[24] Cerda, J. and Cifuentes, L. (2012) Using ROC Curves in Clinical Research. Theoretical and Practical Aspects. Revista Chilena de Infectología, 29, 138-114. http://dx.doi.org/10.4067/S0716-10182012000200003

[25] Bele, N., Darmon, M., Coquet, I., Feugeas, J.P., Legriel, S., Adaoui, N., et al. (2011) Diagnostic Accuracy of Procalcitonin in Critically Ill Immunocompromised Patients. BMC Infectious Diseases, 11, 224. http://dx.doi.org/10.1186/1471-2334-11-224

[26] Massaro, K.S., Costa, S.F., Leone, C. and Chamone, D. (2007) Procalcitonin (PCT) and C-Reactive Protein (CRP) as Severe Systemic Infection Markers in Febrile Neutropenic Adults. BMC Infectious Diseases, 7, 137. http://dx.doi.org/10.1186/1471-2334-7-137 
Scientific Research Publishing (SCIRP) is one of the largest Open Access journal publishers. It is currently publishing more than 200 open access, online, peer-reviewed journals covering a wide range of academic disciplines. SCIRP serves the worldwide academic communities and contributes to the progress and application of science with its publication.

Other selected journals from SCIRP are listed as below. Submit your manuscript to us via either submit@scirp.org or Online Submission Portal.
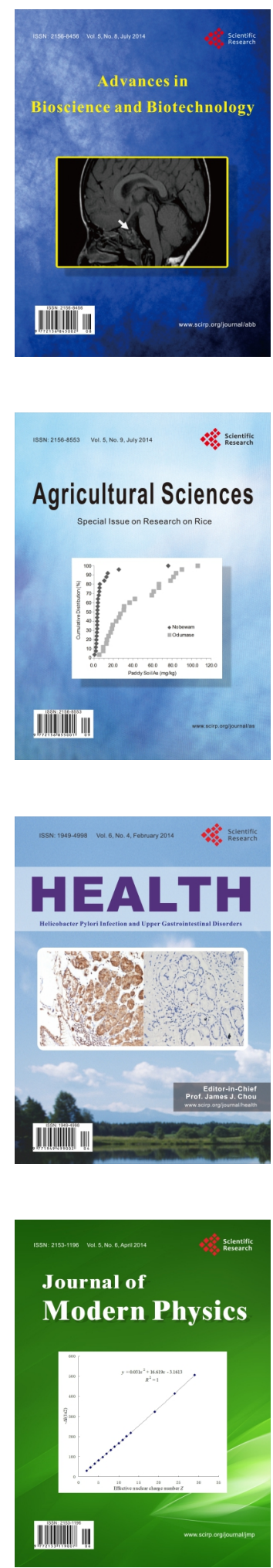
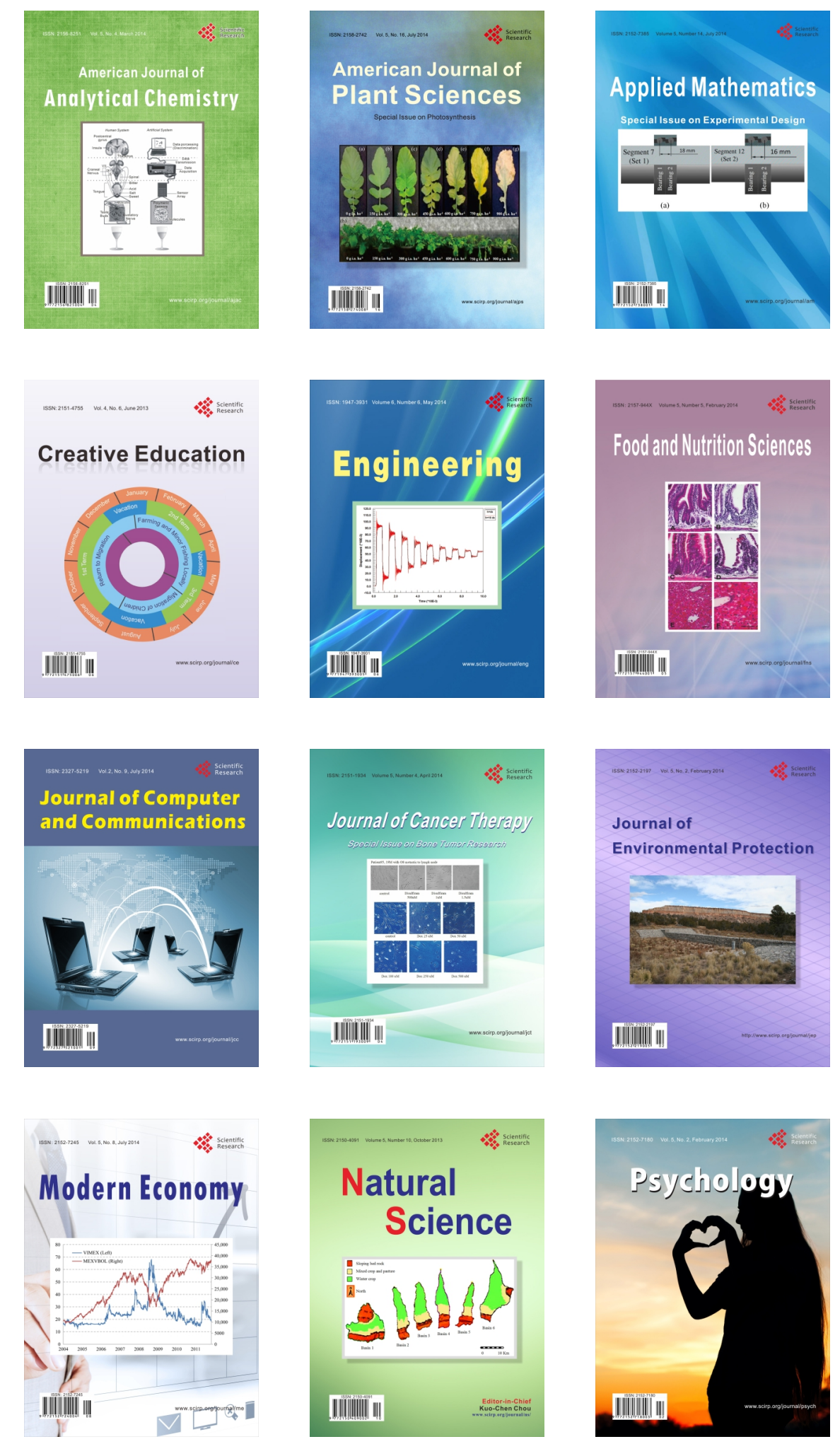